Article

\title{
Mathematical Model of a Lithium-Bromide/Water Absorption Refrigeration System Equipped with an Adiabatic Absorber
}

\author{
Salem M. Osta-Omar * and Christopher Micallef \\ Mechanical Engineering Department, University of Malta, Msida MSD 2080, Malta; \\ christopher.micallef@um.edu.mt \\ * Correspondence: salem.omar.13@um.edu.mt; Tel.: +35-699-357-005 \\ Academic Editor: Qinjun Kang \\ Received: 13 October 2016; Accepted: 11 November 2016; Published: 17 November 2016
}

\begin{abstract}
The objective of this paper is to develop a mathematical model for thermodynamic analysis of an absorption refrigeration system equipped with an adiabatic absorber using a lithium-bromide/water ( $\mathrm{LiBr}$ /water) pair as the working fluid. The working temperature of the generator, adiabatic absorber, condenser, evaporator, the cooling capacity of the system, and the ratio of the solution mass flow rate at the circulation pump to that at the solution pump are used as input data. The model evaluates the thermodynamic properties of all state points, the heat transfer in each component, the various mass flow rates, and the coefficient of performance (COP) of the cycle. The results are used to investigate the effect of key parameters on the overall performance of the system. For instance, increasing the generator temperatures and decreasing the adiabatic absorber temperatures can increase the $\mathrm{COP}$ of the cycle. The results of this mathematical model can be used for designing and sizing new $\mathrm{LiBr}$ /water absorption refrigeration systems equipped with an adiabatic absorber or for optimizing existing aforementioned systems.
\end{abstract}

Keywords: absorption refrigeration system; adiabatic absorber; LiBr/water solution

\section{Introduction}

The absorption refrigeration cycle is similar to the conventional compression refrigeration cycle, having the compressor replaced by an absorber, pump, and generator. The compression refrigeration cycle is described as a work-operated cycle, since work input at the compressor is required to lift the refrigerant from the low side pressure to high side pressure. On the other hand, the lifting process of the vapor refrigerant pressure in the absorption refrigeration system is accomplished by three steps; absorbing vapor refrigerant in weak $\mathrm{LiBr}$ /water solution while removing heat in the absorber, elevating the pressure of the strong $\mathrm{LiBr} /$ water solution resulting from the absorption process and delivering it to the generator at high pressure using a pump, and driving off vapor refrigerant by applying heat in a generator. For this reason, the absorption refrigeration cycle is better known as a heat-operated cycle [1]. In some applications, where a compact absorber is needed, solution sub-coolers are added to the cycle, in order to extract the heat of the absorption process from the $\mathrm{LiBr} /$ water solution, as shown in Figure 1. The flow of the solutions are driven by solution and circulation pumps. This type of system is known as the $\mathrm{LiBr} /$ water absorption refrigeration system equipped with an adiabatic absorber [2,3]. 


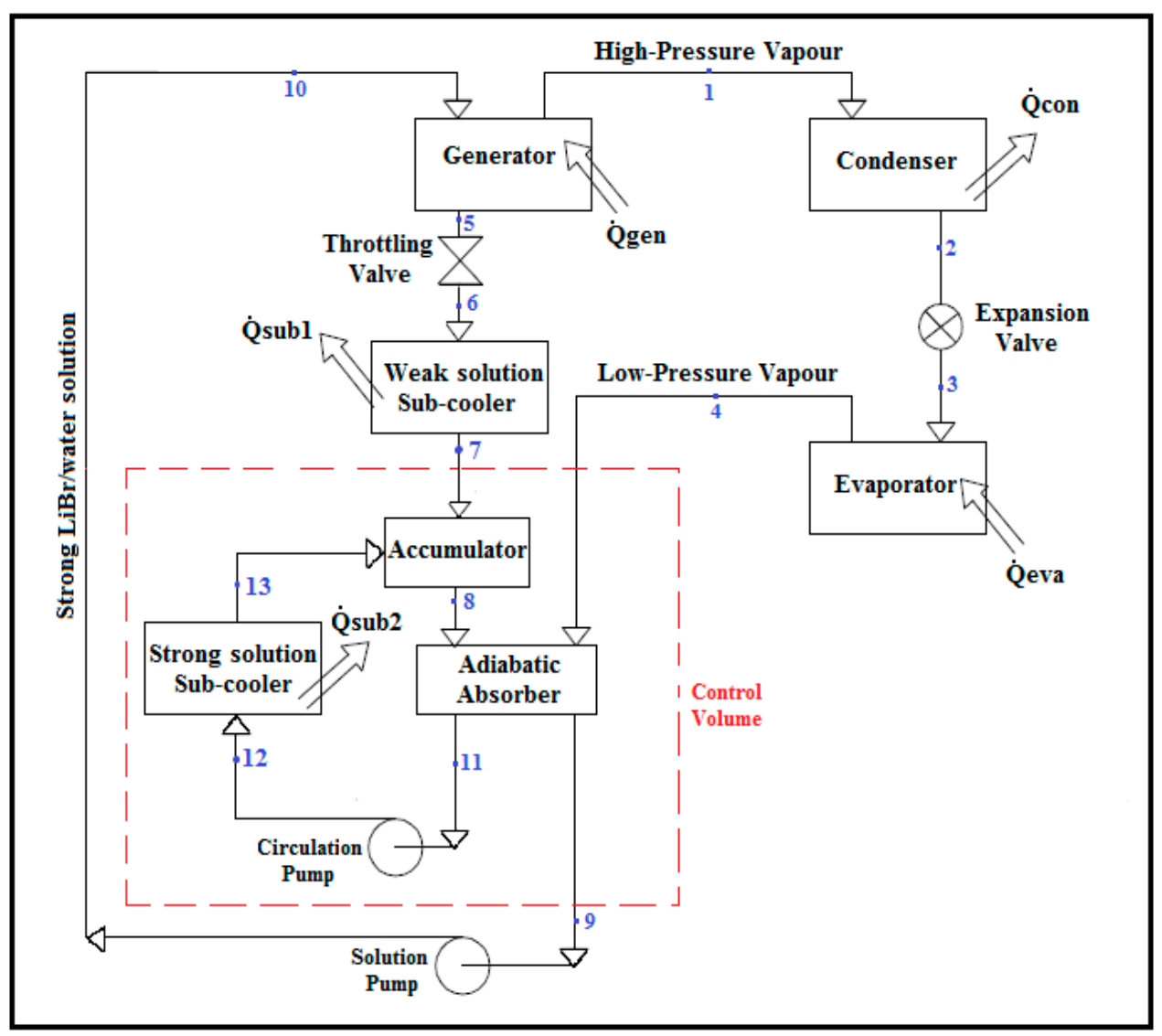

Figure 1. Schematic diagram of a $\mathrm{LiBr}$ /water (lithium-bromide/water) absorption refrigeration system equipped with an adiabatic absorber.

Many published mathematical models and experimental studies of the absorption refrigeration systems show that the COP (coefficient of performance) of the absorption system is greatly influenced by the system temperatures [4-7]. The effect of the parameters, like the generator, absorber, condenser, and evaporator temperature, on the COP of the absorption refrigeration system have been experimentally studied by Eisa and Holland [4], and the result shows that the most significant parameter affecting the $\mathrm{COP}$ of the cycle is the generator temperature, where an increase in generator temperature increases the COP. Another experimental study by Eisa et al. [5] shows that an increase in the difference between the temperatures of the absorber and condenser decreases the cooling effect and COP of the absorption refrigeration system. Also, a theoretical study by Micallef and Micallef [6] shows that the COP of the absorption refrigeration cycle increases when the generator temperature increases or the absorber temperature decreases.

According to Samanta and Basu [7], the optimum generator temperature can be identified for each combination of condenser and evaporator temperatures and, in the case of a solar powered absorption system, the optimum generator temperature is $75^{\circ} \mathrm{C}$ when the condenser and evaporator temperatures are $40{ }^{\circ} \mathrm{C}$ and $15{ }^{\circ} \mathrm{C}$, respectively. The design and performance study of an absorption system by Sharma et al. [8] concludes that a decrease in the exit concentration of the $\mathrm{LiBr} /$ water solution at the absorber, or an increase in the evaporator pressure, leads to an increase in the COP of the cycle; however, an increase in the condenser pressure decreases the COP of the cycle. A new method for COP optimization of single and double $\mathrm{LiBr} /$ water absorption machines by Marcos et al. [9] shows that an increase in the difference between the LiBr mass concentrations of the strong and weak $\mathrm{LiBr} /$ water solutions $(\Delta C)$ increases the COPs of the cycles up to certain values; above these values, the COPs are only slightly affected by any increase in $\Delta C$, and then any further increase in $\Delta C$ leads to crystallization of the $\mathrm{LiBr} /$ water solution. Additionally, this study concludes that using water as the cooling medium 
to cool the components of the absorption system provides a better margin against crystallization problems than would be the case with air, and excludes the effect of the ambient temperature on the COP of the cycle [9].

A falling column adiabatic $\mathrm{LiBr}$ /water absorption refrigeration unit, where heat and mass transfer can be separated, was experimentally investigated by Jingyuan et al. [10]. Their results showed that the absorption rate of $\mathrm{LiBr}$ / water solution inside the absorber was strongly dependent on the initial solution properties, which are the temperature and LiBr mass concentration of the solution entering the adiabatic absorber. However, the absorption rate is less dependent on the mass flow rate of LiBr/water solution entering the adiabatic absorber and pressure difference between the absorber and evaporator.

Zacarías et al. [11], investigated the dispersion method of the solution inside the adiabatic absorber using a full cone nozzle. Their results show that the absorption process inside the adiabatic absorber is not significantly affected by the height of the nozzle, but the degree of sub-cooling for $\mathrm{LiBr} /$ water solution entering the adiabatic absorber has potentially an effect on the absorption mass transfer.

Experimental results taken from an absorption test rig equipped with an adiabatic absorber were presented by Gutierrez-Urueta et al. [3]. They concluded that the absorption rate and cooling capacity of the system increase when the generator temperature, recirculation ratio of the strong solution to the recirculated solution, and the mass flow rate of weak $\mathrm{LiBr}$ /water solution increase. They also observed that the average loss in cooling capacity due to the overflow of refrigerant from the evaporator to the solution reservoir was about $52 \%$ of total cooling capacity rate.

Fengmin et al. [12] developed an improved analytical Newman model considering the absorption heat effect. The model was used to study the absorption characteristics of the $\mathrm{LiBr} /$ water solution in an adiabatic spray absorber, in which the absorption fluid is dispersed into fine droplets with diameters ranging from $100 \mu \mathrm{m}$ to $500 \mu \mathrm{m}$, resulting in immense absorption surface area of LiBr/water solution exposed to the vapor refrigerant. Their results show that the absorption heat released from phase change of vapor refrigerant significantly decreased absorption mass transfer in the adiabatic spray absorber, and when the droplet radius was reduced, the absorption rate was improved and the maximum absorption time was reduced.

Experimental results on a direct air-cooled $\mathrm{LiBr} /$ water absorption machine were presented by González-Gil et al. [13]. The distribution of the LiBr/water solution inside the absorber was in flat-fan sheets style, which allowed for a compact design of the absorber. Generally, the numerical model predictions were in agreement with experimental results to within $10 \%$. It was concluded that, for an absorber equipped with 18 flat-fan sheet injectors, for a $4.5 \mathrm{~kW}$ single-effect system the cooling air flow rate required was $1.6 \mathrm{~kg} / \mathrm{s}$, and for a $7 \mathrm{~kW}$ double-effect system the cooling air flow rate required was $2.2 \mathrm{~kg} / \mathrm{s}$. According to the authors, due to heat transfer limitations, there was a higher risk of crystallization when using air-cooled absorbers compared to water-cooled absorbers.

An air-cooled adiabatic absorption refrigeration system with a falling film absorber was theoretically investigated and developed by Wang et al. [14] to improve the performance of the conventional air-cooled absorption refrigeration systems. Low-temperature and high-temperature heat exchangers were added to the cycle in order to conserve energy and boost the COP. The exothermic heat due to the absorption process was rejected using an air-cooled heat exchanger. The results showed that both mass transfer in the adiabatic absorber and heat transfer in the air cooler could be effectively enhanced at the same time. Moreover, numerical results indicated that low solution distribution ratio in the adiabatic absorber enhanced the operation of the cycle in a vacuum state and increased the COP of the cycle, but it also increased the risk of crystallization in the high-temperature heat exchanger.

This paper presents a mathematical model of an $\mathrm{LiBr} /$ water absorption refrigeration system equipped with an adiabatic absorber. An efficient mathematical method of solving the mathematical model is also presented. Furthermore, the effect of key parameters, such as the generator and adiabatic absorber temperatures and the $\mathrm{LiBr}$ mass concentrations of the weak and strong $\mathrm{LiBr} /$ water solutions, on the $\mathrm{COP}$ of a $\mathrm{LiBr} /$ water absorption refrigeration system equipped with an adiabatic absorber having a cooling capacity of $1 \mathrm{~kW}$, is analyzed. 


\section{System Description}

With reference to the numbering system shown in Figure 1, at point (1) the superheated refrigerant vapor flows to the condenser, where it is condensed. Heat $\left(\dot{Q}_{c o n}\right)$ is rejected to an external sink in the condenser. The condensed liquid refrigerant at point (2) flows through the expansion valve to point (3), where it enters the evaporator. In the evaporator, the refrigerant is evaporated by gaining heat from the surroundings, producing a cooling effect $\left(\dot{Q}_{\text {eva }}\right)$. The evaporated refrigerant at point $(4)$ is absorbed by the $\mathrm{LiBr}$ /water solution entering into the adiabatic absorber, producing a strong $\mathrm{LiBr}$ /water solution.

A small portion of the refrigerant may leave the evaporator as liquid spillover into the absorber via an overflow pipe. This portion is not included in the calculation because of its small effect on the result; thereby it is neglected. The strong $\mathrm{LiBr}$ /water solution produced in the adiabatic absorber flows in two separate streams; one stream is pumped from the adiabatic absorber to the generator through the solution pump (path 9-10), while another stream is pumped from the adiabatic absorber to the strong solution sub-cooler through the circulation pump (path 11-12). In the strong solution sub-cooler, the heat generated by the exothermic absorption process in the adiabatic absorber is rejected to the external sink $\left(\dot{Q}_{\text {sub } 2}\right)$.

In the absorption refrigeration system, the pump work is negligible compared to heat input at the generator, and therefore it is neglected in this analysis. In the generator, heat energy $\left(\dot{Q}_{g e n}\right)$ is supplied to boil the refrigerant out of the strong $\mathrm{LiBr} /$ water solution at the generator, thus producing a refrigerant vapor at point (1) and a weak $\mathrm{LiBr} /$ water solution at point (5). This weak $\mathrm{LiBr} /$ water solution flows back to the adiabatic absorber through the following components: a throttling valve, where the pressure of the weak $\mathrm{LiBr}$ /water solution at point (5) is reduced to the adiabatic absorber pressure at point (6), followed by the weak solution sub-cooler, where the temperature of the weak $\mathrm{LiBr} /$ water solution at point (6) is dropped to the adiabatic absorber temperature $\left(T_{a b s}=T_{9}=T_{11}\right)$ at point (7) while rejecting heat $\left(\dot{Q}_{s u b 1}\right)$ to the external sink, and then the accumulator, where the weak $\mathrm{LiBr}$ /water solution at point (7) is mixed adiabatically with the strong $\mathrm{LiBr}$ /water solution at point (13), producing a mixture of $\mathrm{LiBr}$ /water solutions at point (8). This mixture is the sorbent $\mathrm{LiBr} /$ water solution entering the adiabatic absorber at a temperature below the adiabatic absorber temperature and with a $\mathrm{LiBr}$ mass concentration higher than the strong $\mathrm{LiBr} /$ water solution at point (11) and lower than the weak $\mathrm{LiBr}$ /water solution at point (7), depending on the circulation flow rate.

The input thermal energy in the generator is equal to both the energy required for the refrigerant to change from a liquid phase to a vapor phase, and the energy required to break the intermolecular bonds formed between the refrigerant and the strong solution. Therefore, the total thermal energy input in the generator, which is required to separate the refrigerant from the solution, is around $15 \%$ more than the thermal energy required to boil the refrigerant alone, and this additional energy is known as the heat of mixing [15]. As a result, the refrigerant vapor produced in the generator is in a superheated vapor state rather than in a saturated vapor state.

To establish the design parameters and to simplify the modeling of an $\mathrm{LiBr} /$ water absorption refrigeration system equipped with an adiabatic absorber, the following assumptions were made:

1. The refrigerant at the exit of the evaporator is saturated vapor (no liquid spillover).

2. The solutions which leave the adiabatic absorber and the generator are saturated liquid at the units' temperatures.

3. The adiabatic absorber pressure is equal to the evaporator pressure and the generator pressure is equal to the condenser pressure.

4. The solution entering the generator is at the generator pressure.

5. The throttling and pumping processes are adiabatic.

6. The solution and circulation pumps' work are negligible.

7. The solution leaving the weak solution sub-cooler is at the adiabatic absorber temperature.

8. The adiabatic absorber and the accumulator are insulated well. 
The mathematical model of the absorption refrigeration system is based on the equilibrium of the pressure between the $\mathrm{LiBr} /$ water solution in the absorber and the refrigerant in the evaporator, and the equilibrium of the pressure between the $\mathrm{LiBr} /$ water solution in the generator and the refrigerant in the condenser [1]. This is reflected in assumption 3. Additionally, it is assumed that the inlet and outlet temperatures of the $\mathrm{LiBr} /$ water solutions crossing the control volume are equal at points (7) $\&(9)$, as a result of which, only the amount of heat generated by the exothermic absorption process in the adiabatic absorber is rejected at the strong solution sub-cooler, and this is reflected in assumption 7.

In reality, there are slight differences in pressures between the absorber and the evaporator and also between the generator and the condenser. The solution vapor pressure in the generator is slightly higher than the refrigerant vapor pressure in the condenser. This pressure difference is the driving force of refrigerant flow from the generator to the condenser. Also, the refrigerant vapor pressure in the evaporator is slightly higher than the solution vapor pressure in the absorber; thereby, the absorption process takes place [16].

The $\mathrm{LiBr} /$ water absorption refrigeration system equipped with an adiabatic absorber was analyzed based on the following specification:

1. A cooling capacity $\left(\dot{Q}_{\text {eva }}\right)$ at the evaporator of $1 \mathrm{~kW}$.

2. The temperature of the condenser $\left(T_{c o n}=T_{2}\right)$ was set to $35^{\circ} \mathrm{C}$, which is a suitable temperature for the external sink to the condenser.

3. The evaporator temperature $\left(T_{\text {eva }}=T_{4}\right)$ was set to $10^{\circ} \mathrm{C}$, which is a suitable temperature when using water as refrigerant.

4. The range of temperatures of the generator $\left(T_{\text {gen }}=T_{1}=T_{5}\right)$ considered was $65-90{ }^{\circ} \mathrm{C}$.

5. The range of temperatures of the absorber $\left(T_{a b s}=T_{9}=T_{11}\right)$ considered was $25-50{ }^{\circ} \mathrm{C}$.

6. The ratio $(X)$ of the solution mass flow rate at the circulation pump to that at the solution pump was set to 25 .

The LiBr mass concentration and specific enthalpy of the $\mathrm{LiBr} /$ water solutions were estimated using correlations available from the ASHRAE Handbook [17]. Most of the absorption systems use solutions with a concentration of less than $65 \%$ by mass of lithium-bromide in solution, to avoid crystallization problems [18]. Consequently, the concentration of the weak LiBr/water solutions was kept below $65 \%$ in this thermodynamic analyses. The specific enthalpy of water and vapor refrigerant was determined using a steam liberary for water and steam properties according to IAPWS IF-97 [19].

\section{Mathematical Model}

The following equations mathematically describe the $\mathrm{LiBr} /$ water absorption refrigeration system equipped with an adiabatic absorber:

- Throttling process between stations 2 \& 3 and between stations 5 \& 6; applying the steady state energy equation across the throttling and expansion valves:

$$
h_{3}=h_{2} \text { and } h_{6}=h_{5}
$$

- $\quad$ Pumping process between stations $9 \& 10$ and between stations 11 \& 12; applying the steady state energy equation across the solution and circulation pumps (neglecting pumps' work):

$$
h_{10}=h_{9} \text { and } h_{12}=h_{11}
$$

- $\quad$ Refrigerant circuit between stations 1, 2, 3, \& 4; applying the mass conservation equation:

$$
\dot{m}_{1}=\dot{m}_{2}=\dot{m}_{3}=\dot{m}_{4}
$$


- Evaporation process between stations 3 \& 4; applying the steady state energy equation across the evaporator:

$$
\dot{m}_{4}=\frac{\dot{Q}_{e v a}}{\left(h_{4}-h_{3}\right)}
$$

- Condensation process between stations 1 \& 2; applying the steady state energy equation across the condenser:

$$
\dot{Q}_{\text {con }}=\dot{m}_{1} \times h_{1}-\dot{m}_{2} \times h_{2}
$$

- Lithium-bromide mass balance between stations 5, 6, \& 7 yields:

$$
C_{5}=C_{6}=C_{7}
$$

- Lithium-bromide mass balance between stations 9 \& 10 yields:

$$
C_{9}=C_{10}
$$

- Lithium-bromide mass balance between stations $11,12, \& 13$ yields:

$$
C_{11}=C_{12}=C_{13}
$$

where $h$ is the specific enthalpy $(\mathrm{kJ} / \mathrm{kg}), \dot{m}$ is the mass flow rate $(\mathrm{kg} / \mathrm{s}), \dot{Q}_{\text {eva }}$ is the cooling capacity at the evaporator $(\mathrm{kW}), \dot{Q}_{c o n}$ is the heat reject at the condenser $(\mathrm{kW})$, and $C$ is the LiBr mass concentration of $\mathrm{LiBr} /$ water solution (\%).

In order to perform the thermodynamic analysis of the $\mathrm{LiBr}$ /water absorption refrigeration system equipped with an adiabatic absorber, three groups of equations need to be solved (Equations (1)-(8), Equations (9)-(16), \& Equations (17)-(24)). The first group of eight equations (Equations (1)-(8)) relate to the refrigeration section (branches 1, 2, 3, \& 4), lithium-bromide mass balance, and the energy balance at the throttling and expansion valves and at the solution and circulation pumps. The unknowns in Equations (1)-(8) may be evaluated directly from system and fluids properties. The next set of eight equations (Equations (9)-(16)) relate to the mass and energy balances at the generator, the mass balance at the throttling valve and solution pump, the energy balance at the weak solution sub-cooler, and the mass and energy balances across the control volume. These equations need to be solved simultaneously in order to evaluate the eight unknown variables.

- Applying the mass and $\mathrm{LiBr}$ mass conservation equations and the steady state energy equation across the generator:

$$
\begin{gathered}
\dot{m}_{10}-\dot{m}_{5}=\dot{m}_{1} \\
C_{10} \times \dot{m}_{10}-C_{5} \times \dot{m}_{5}=0 \\
\dot{m}_{10} \times h_{10}-\dot{m}_{5} \times h_{5}+\dot{Q}_{\text {gen }}=\dot{m}_{1} \times h_{1}
\end{gathered}
$$

- Applying the mass conservation equation across the throttling valve:

$$
\dot{m}_{5}-\dot{m}_{6}=0
$$

- Applying the mass conservation equation across the solution pump:

$$
\dot{m}_{9}-\dot{m}_{10}=0
$$

- Applying the steady state energy equation across the weak solution sub-cooler:

$$
\dot{m}_{6} \times h_{6}-\dot{m}_{7} \times h_{7}-\dot{Q}_{s u b 1}=0
$$


- Applying the mass conservation equation and the steady state energy equation across the control volume shown in Figure 1:

$$
\begin{gathered}
\dot{m}_{7}-\dot{m}_{9}=-\dot{m}_{4} \\
\dot{m}_{7} \times h_{7}-\dot{m}_{9} \times h_{9}-\dot{Q}_{s u b 2}=-\dot{m}_{4} \times h_{4}
\end{gathered}
$$

where $\dot{Q}_{g e n}$ is the heat input at the generator, $\dot{Q}_{s u b 1}$ is the heat reject at the weak solution sub-cooler, and $\dot{Q}_{s u b 2}$ is the heat reject at the strong solution sub-cooler.

The last set of equations (Equations (17)-(24)) refers to the circulation pump mass balance, strong solution sub-cooler mass and energy balances, accumulator mass, LiBr mass, and energy balances, and calculating of the COP. The unknown variables in Equations (17)-(24) may be evaluated directly.

- From the ratio $(X)$ of the solution mass flow rate at the circulation pump to that at the solution pump:

$$
\dot{m}_{11}=\mathrm{X} \times \dot{m}_{9}
$$

- Applying the mass conservation equation across the circulation pump:

$$
\dot{m}_{12}=\dot{m}_{11}
$$

- Applying the mass conservation equation and the steady state energy equation across the strong solution sub-cooler:

$$
\begin{gathered}
\dot{m}_{13}=\dot{m}_{12} \\
h_{13}=\frac{\dot{m}_{12} \times h_{12}-\dot{Q}_{s u b 2}}{\dot{m}_{13}}
\end{gathered}
$$

- Applying the mass and $\mathrm{LiBr}$ mass conservation equations and the steady state energy equation across the accumulator:

$$
\begin{gathered}
\dot{m}_{8}=\dot{m}_{7}+\dot{m}_{13} \\
C_{8}=\frac{C_{7} \times \dot{m}_{7}+C_{13} \times \dot{m}_{13}}{\dot{m}_{8}} \\
h_{8}=\frac{\dot{m}_{7} \times h_{7}+\dot{m}_{13} \times h_{13}}{\dot{m}_{8}}
\end{gathered}
$$

- The coefficient of performance (COP) of a $\mathrm{LiBr} /$ water absorption refrigeration cycle is defined as:

$$
C O P=\frac{\text { Cooling capacity at the evaporator }}{\text { Rate of heat input at the generator }}=\frac{\dot{Q}_{\text {eva }}}{\dot{Q}_{\text {gen }}}
$$

\section{Model Implementation}

The algorithm describing the mathematical model shown in Figure 2 was implemented in MATLAB 2010 [20]. The second set of equations (Equations (9)-(16)) were solved using inverse matrix technique (Equations (25) and (26)). Matrix A consists of the coefficients of mass and energy balance conservation equations, and matrix $X$ consists the unknown design parameters. Matrix $B$ consists of quantities found previously by solving the first set of equations (Equations (1)-(8)).

$$
[\mathrm{A}][\mathrm{X}]=[\mathrm{B}]
$$




$$
\left[\begin{array}{cccccccc}
-1 & 0 & 0 & 0 & 1 & 0 & 0 & 0 \\
-C_{5} & 0 & 0 & 0 & C_{10} & 0 & 0 & 0 \\
-h_{5} & 0 & 0 & 0 & h_{10} & 0 & 0 & 1 \\
1 & -1 & 0 & 0 & 0 & 0 & 0 & 0 \\
0 & 0 & 0 & 1 & -1 & 0 & 0 & 0 \\
0 & h_{6} & -h_{7} & 0 & 0 & -1 & 0 & 0 \\
0 & 0 & 1 & -1 & 0 & 0 & 0 & 0 \\
0 & 0 & h_{7} & -h_{9} & 0 & 0 & -1 & 0
\end{array}\right]\left[\begin{array}{c}
\dot{m}_{5} \\
\dot{m}_{6} \\
\dot{m}_{7} \\
\dot{m}_{9} \\
\dot{m}_{10} \\
\dot{Q}_{\text {sub } 1} \\
\dot{Q}_{\text {sub } 2} \\
\dot{Q}_{\text {gen }}
\end{array}\right]=\left[\begin{array}{c}
\dot{m}_{1} \\
0 \\
\dot{m}_{1} \times h_{1} \\
0 \\
0 \\
0 \\
-\dot{m}_{4} \\
-\dot{m}_{4} \times h_{4}
\end{array}\right]
$$

This implementation was used to estimate the design parameters of the $\mathrm{LiBr} /$ water absorption refrigeration system equipped with an adiabatic absorber. Moreover, the MATLAB 2010 program was used to plot the coefficient of performance contour and other graphs relating to the design parameters.

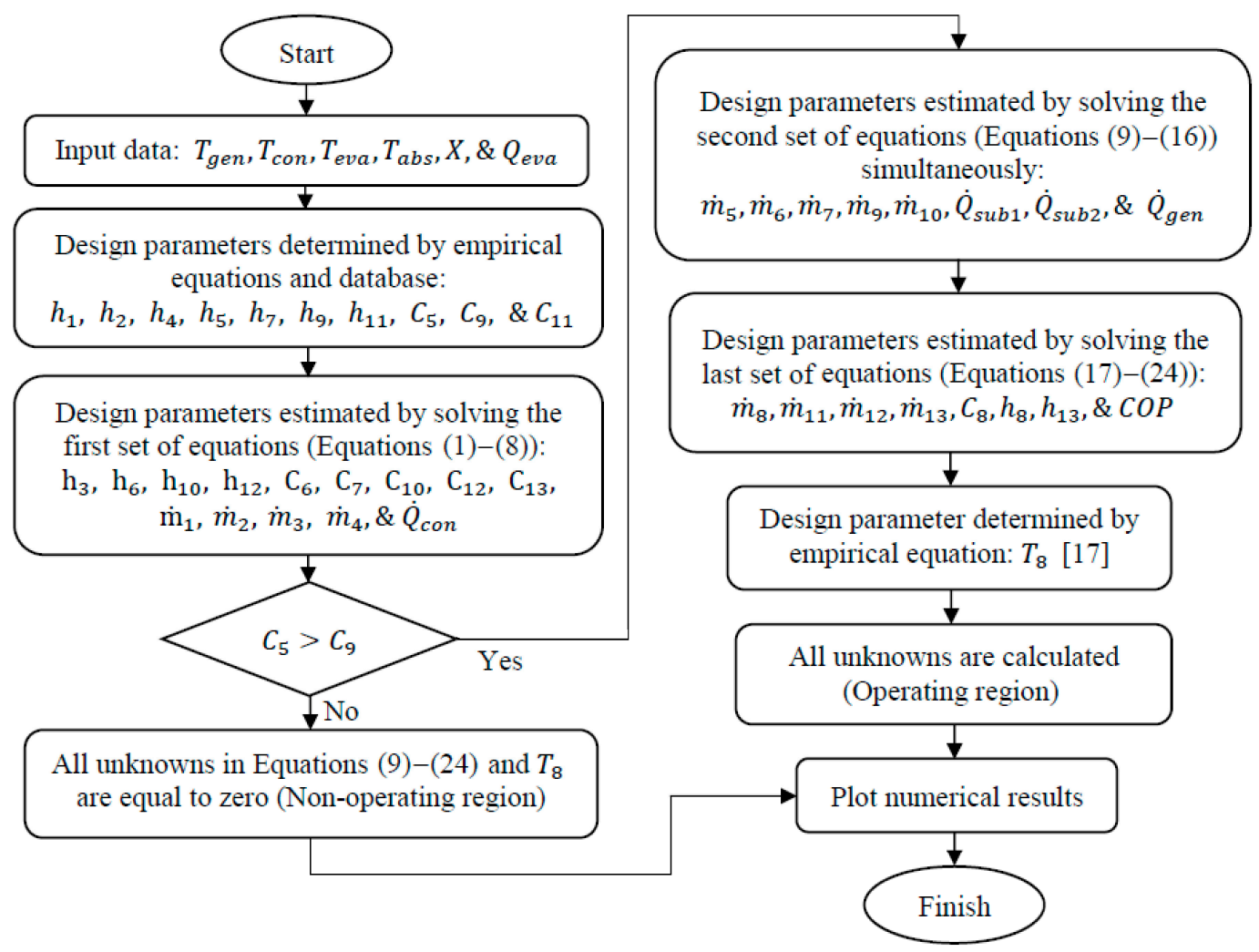

Figure 2. Program flowchart of an $\mathrm{LiBr} /$ water absorption refrigeration system equipped with an adiabatic absorber.

\section{Numerical Results}

Figure 3 illustrates the contour plot of the coefficient of performance of the LiBr/water absorption refrigeration system equipped with an adiabatic absorber against generator temperature $\left(T_{g e n}\right)$ and adiabatic absorber temperature $\left(T_{a b s}\right)$ when the condenser temperature $\left(T_{c o n}\right)$ and evaporator temperature $\left(T_{e v a}\right)$ are fixed at $35^{\circ} \mathrm{C}$ and $10{ }^{\circ} \mathrm{C}$, respectively.

In Figure 3, there are both operating and non-operating regions. The values of the COP ranges between 0.1 up to 0.77 for the operating region. However, by default, the COP value is zero for the non-operational region. In order for the absorption refrigeration system to operate successfully, the $\mathrm{LiBr}$ mass concentration of the solution flowing from the generator to the adiabatic absorber must be larger than that of the solution flowing from the adiabatic absorber to the generator. When this is not the case, the system is said to be non-operational. 


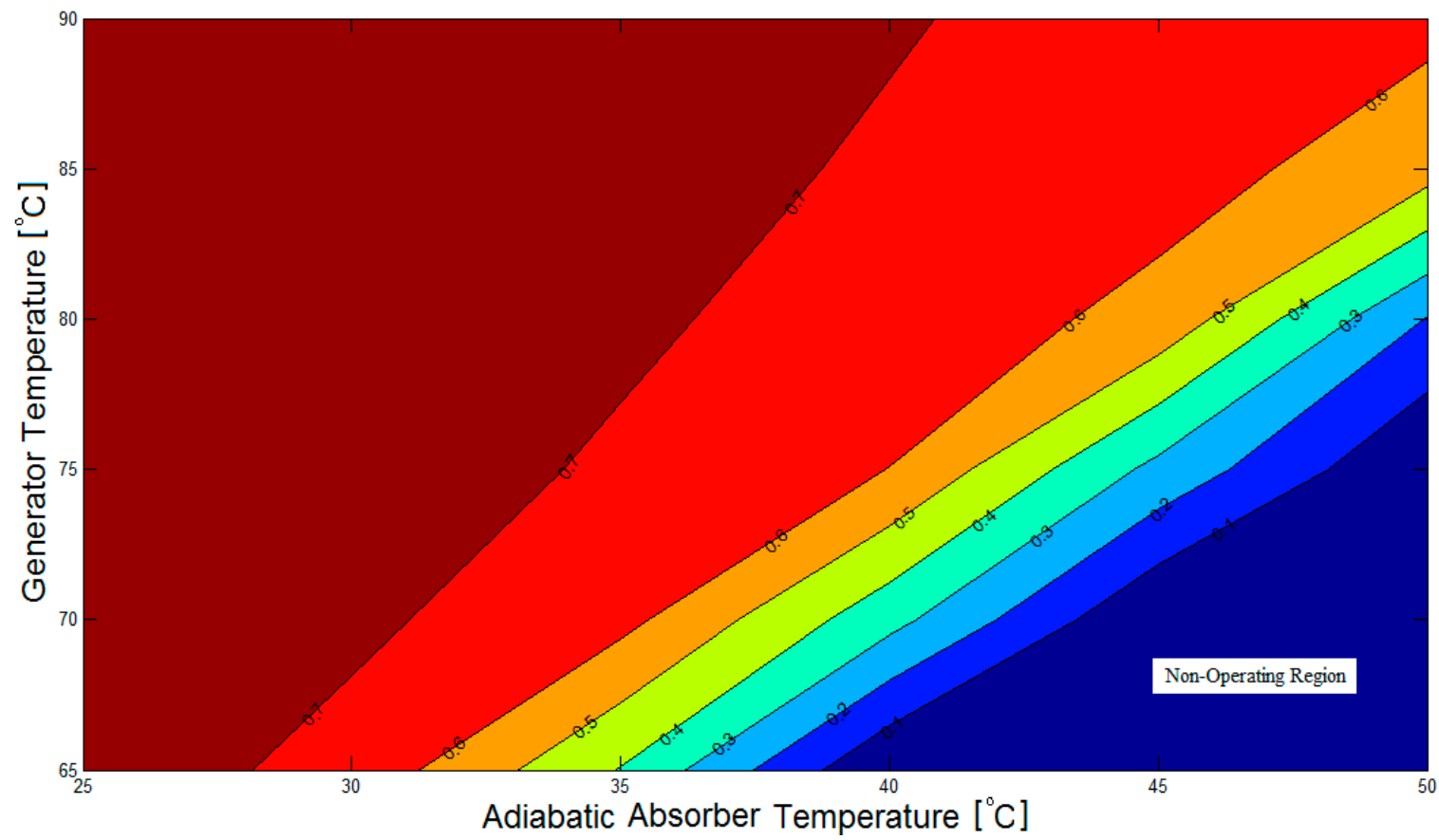

Figure 3. Contour plot of the COP (coefficient of performance) of the $\mathrm{LiBr} /$ water absorption refrigeration system equipped with an adiabatic absorber $\left(T_{c o n}=35^{\circ} \mathrm{C}, T_{\text {eva }}=10^{\circ} \mathrm{C}\right)$.

Figures 4-10 show other numerical results from this mathematical model. As shown in Figure 4a, the $\mathrm{LiBr}$ mass concentration of the weak solution in the generator increases with increasing generator temperatures, and is independent of the adiabatic absorber temperature.

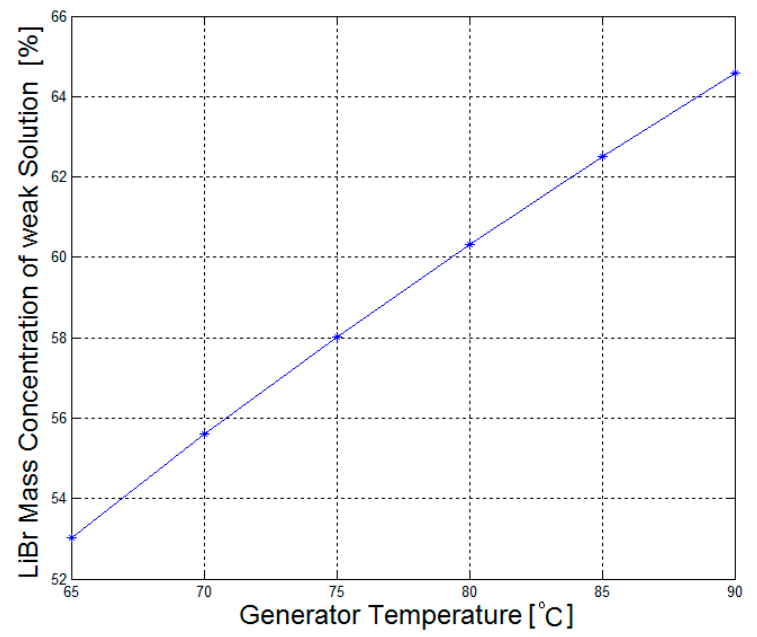

(a)

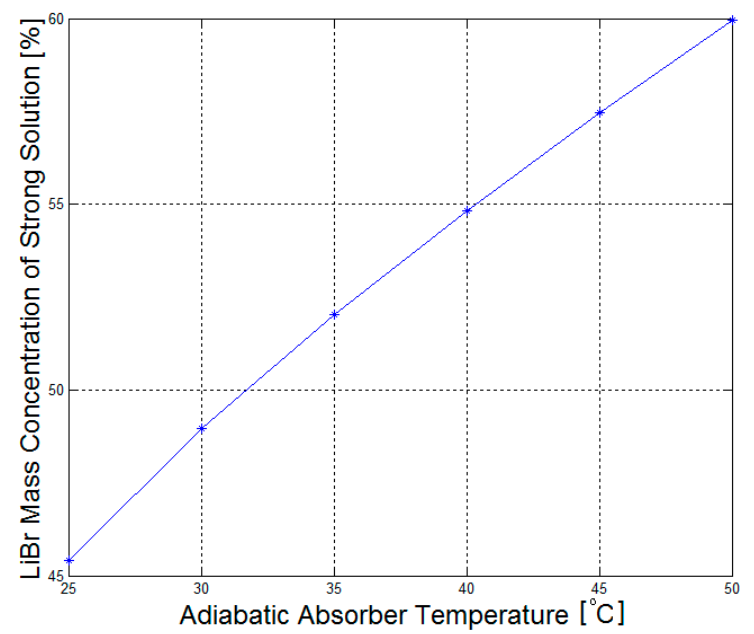

(b)

Figure 4. Graphs showing the variation of the $\mathrm{LiBr}$ mass concentration of: (a) the weak solution with generator temperature $\left(T_{c o n}=35{ }^{\circ} \mathrm{C}, T_{e v a}=10^{\circ} \mathrm{C}\right)$; and $(\mathbf{b})$ the strong solution with adiabatic absorber temperature $\left(T_{\text {con }}=35^{\circ} \mathrm{C}, T_{\text {eva }}=10^{\circ} \mathrm{C}\right)$.

A similar trend can be seen in Figure $4 b$, where the $\mathrm{LiBr}$ mass concentration of the strong solution increases with increasing adiabatic absorber temperature, and is independent of the generator temperature. The relations between the LiBr mass concentration of the solutions and the associated temperatures of the components are almost linear. 
However, Figure 5 shows that the $\mathrm{LiBr}$ mass concentration of the solution entering the adiabatic absorber (point (8) Figure 1) is more sensitive to the generator temperature than to the adiabatic absorber temperature. Also, Figure 4a shows that the $\mathrm{LiBr}$ mass concentration of the weak solution is approximately $65 \%$ when the generator temperature is $90{ }^{\circ} \mathrm{C}$. As previously stated, the absorption refrigeration system should limit the maximum $\mathrm{LiBr}$ mass concentration of the solution to $65 \%$ in order to avoid crystallization problems [18]. Consequently, the maximum generator temperature must be slightly below $90^{\circ} \mathrm{C}$ for an absorption refrigeration system with a cooling capacity of $1 \mathrm{~kW}$, and this temperature may be set at $80^{\circ} \mathrm{C}$ to give a better margin of safety against crystallization.

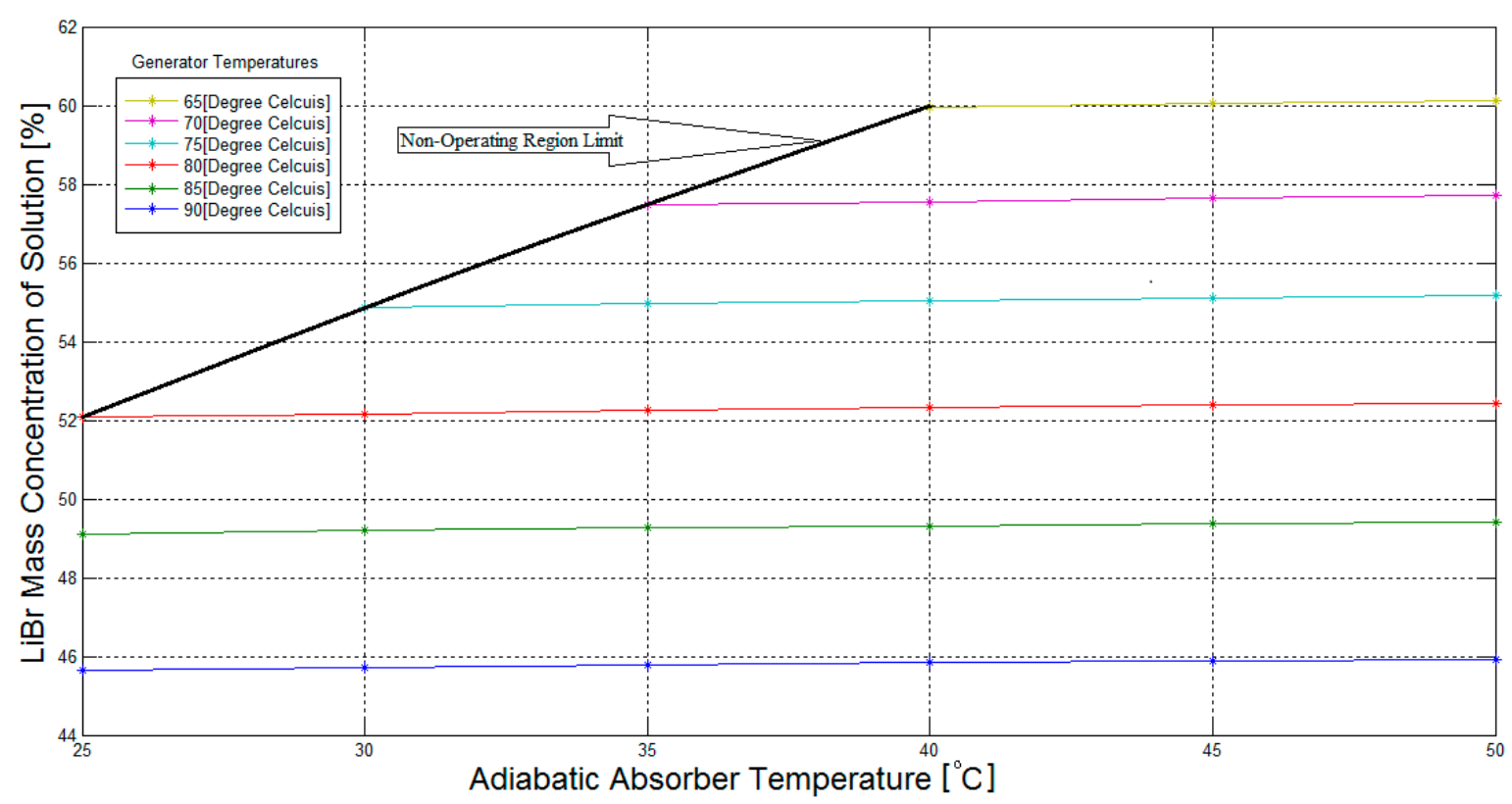

Figure 5. Graph showing the variation of the $\mathrm{LiBr}$ mass concentration of the solution entering the adiabatic absorber, with generator and adiabatic absorber temperatures $\left(T_{\text {con }}=35^{\circ} \mathrm{C}, \mathrm{T}_{\text {eva }}=10^{\circ} \mathrm{C}\right)$.

Figure 6 shows a rapid increase in the generator heat input for the adiabatic absorber temperatures of $35^{\circ} \mathrm{C}, 40^{\circ} \mathrm{C}, 45^{\circ} \mathrm{C}$, and $50{ }^{\circ} \mathrm{C}$, when the generator temperatures are below $70^{\circ} \mathrm{C}, 75^{\circ} \mathrm{C}, 80^{\circ} \mathrm{C}$, and $85^{\circ} \mathrm{C}$, respectively. Also, Figure 7 shows a similar rapid increase in the case of the weak solution sub-cooler heat rejection, for generator temperatures of $65^{\circ} \mathrm{C}, 70^{\circ} \mathrm{C}, 75^{\circ} \mathrm{C}$, and $80^{\circ} \mathrm{C}$, when the adiabatic absorber temperatures are above $30^{\circ} \mathrm{C}, 35^{\circ} \mathrm{C}, 40^{\circ} \mathrm{C}$, and $45^{\circ} \mathrm{C}$, respectively. These areas are synonymous with reduced COP values, as shown in Figure 3 , and thus should be avoided.

The variation of the strong solution sub-cooler heat rejection with generator temperature and adiabatic absorber temperature is shown in Figure 8, while Figure 9 shows the influence of the generator temperature and adiabatic absorber temperature on the $\mathrm{COP}$ of the $\mathrm{LiBr}$ /water absorption refrigeration system equipped with an adiabatic absorber. It can be observed that, as the generator temperature increases, the system COP value increases. From a generator temperature of $65^{\circ} \mathrm{C}-90^{\circ} \mathrm{C}$, the $\mathrm{COP}$ increases rapidly. In contrast, the system COP value increases as the adiabatic absorber temperature decreases.

Figure 10 illustrates the contour plot of the temperature of the $\mathrm{LiBr} /$ water solution entering the adiabatic absorber against the generator and adiabatic absorber temperatures. As can be seen in Figure 10, the temperature of the $\mathrm{LiBr}$ /water solution entering the adiabatic absorber is more sensitive to the adiabatic absorber temperature than to the generator temperature. 


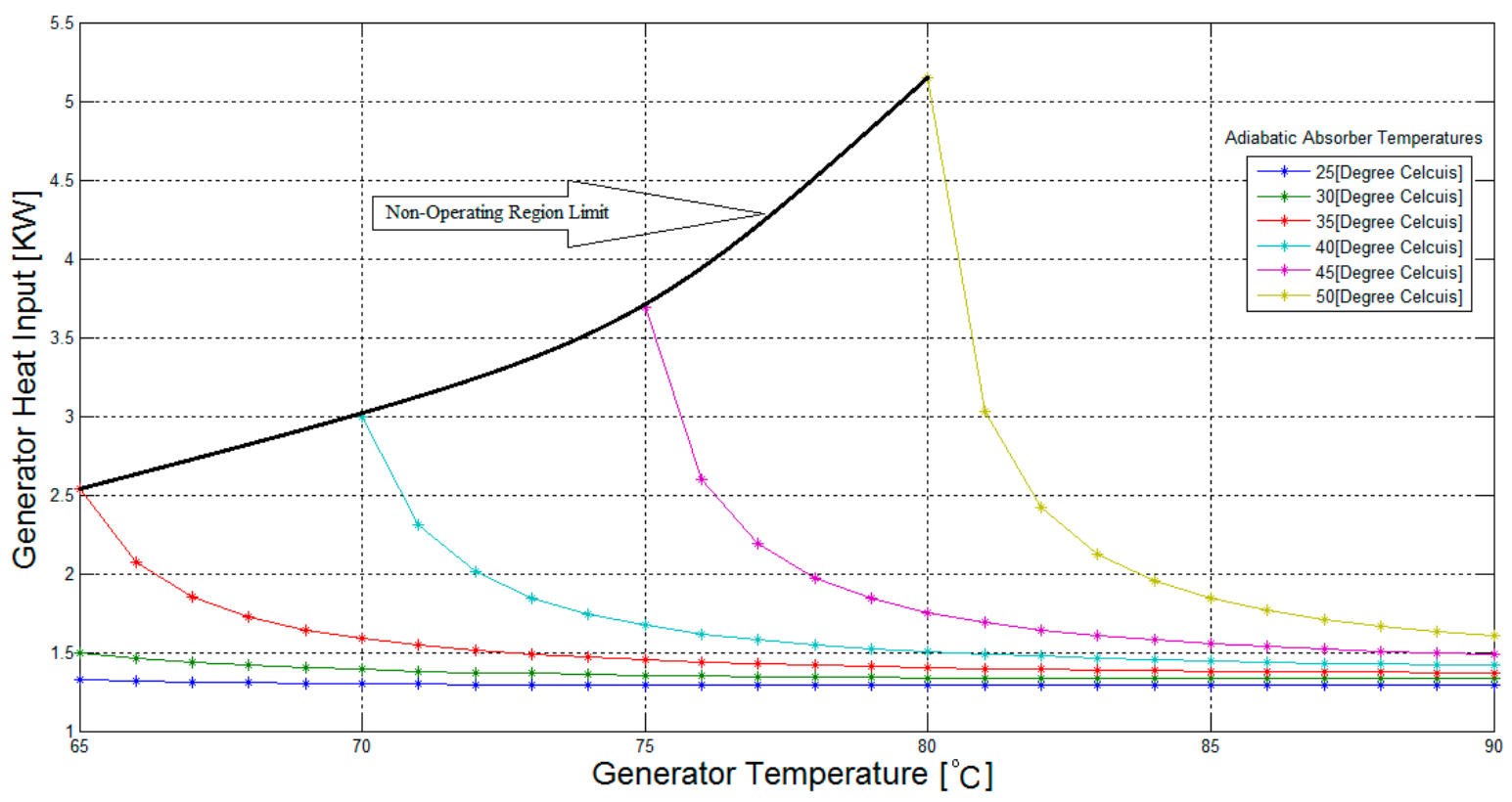

Figure 6. Graph showing the variation of the heat input in the generator, with adiabatic absorber temperature and generator temperature $\left(T_{\text {con }}=35^{\circ} \mathrm{C}, T_{\text {eva }}=10^{\circ} \mathrm{C}\right)$.

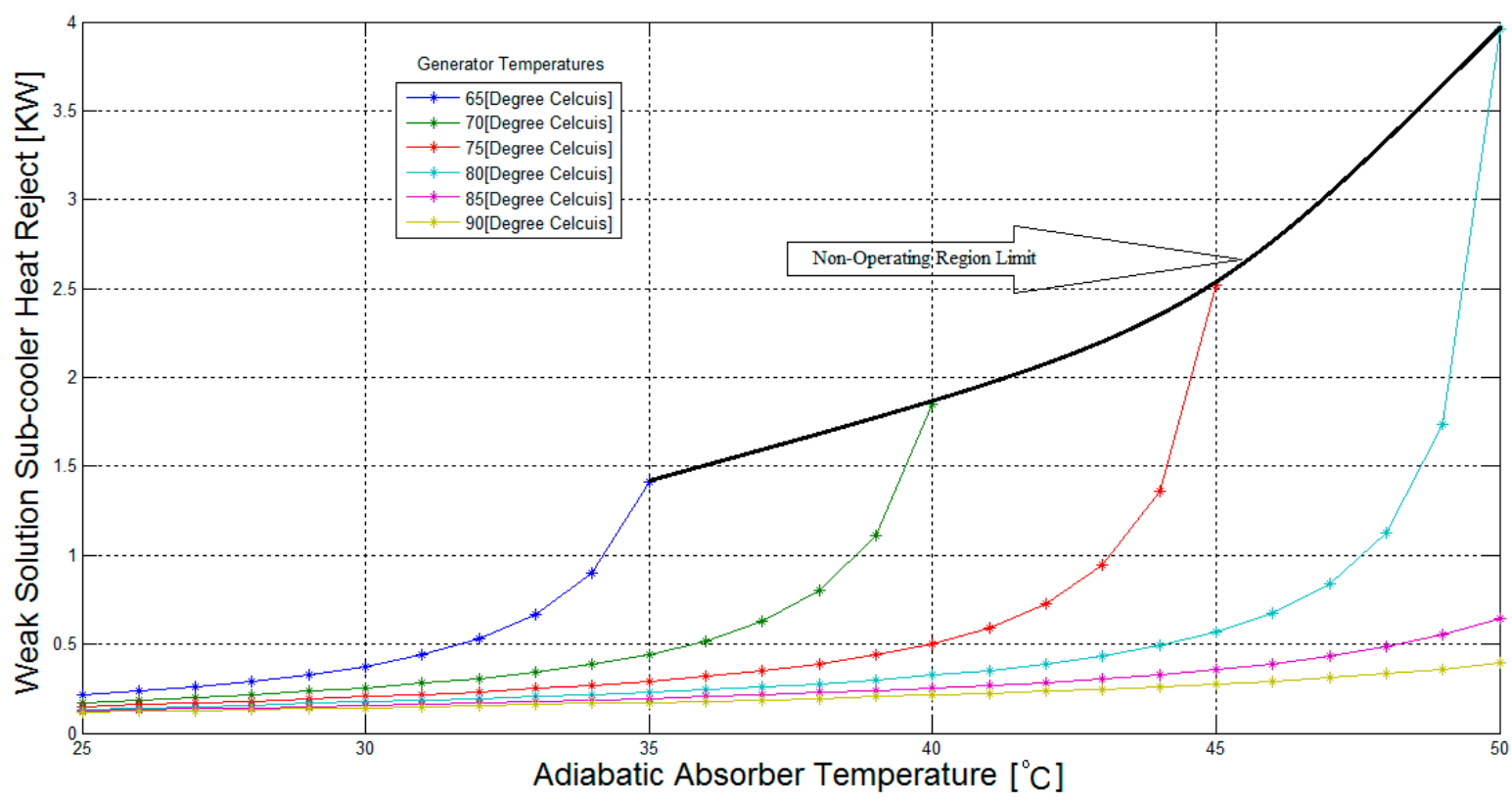

Figure 7. Graph showing the variation of the heat rejection in the weak solution sub-cooler, with generator temperature and adiabatic absorber temperature $\left(T_{\text {con }}=35^{\circ} \mathrm{C}, T_{\text {eva }}=10^{\circ} \mathrm{C}\right)$. 


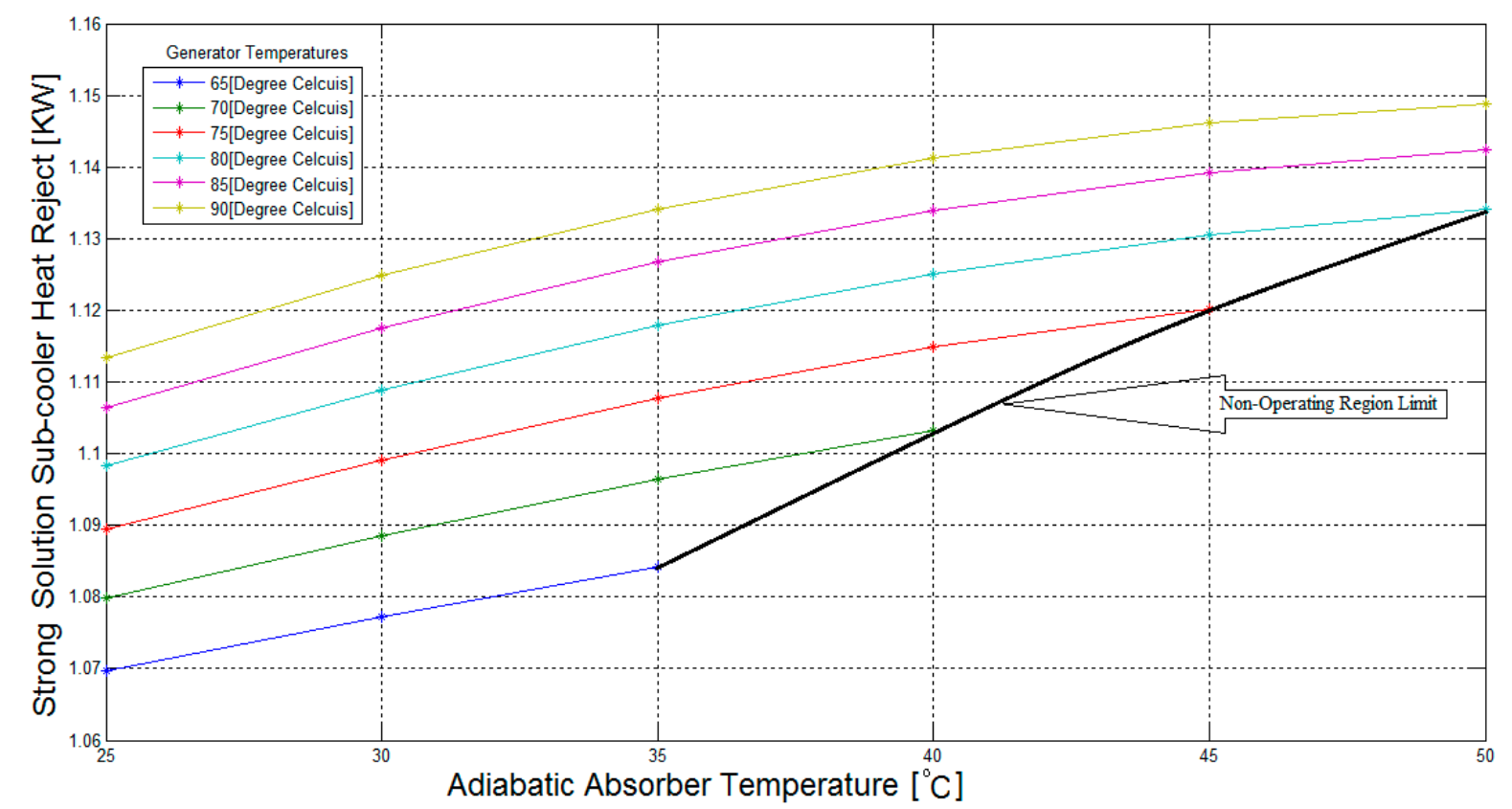

Figure 8. Graph showing the variation of the heat rejection in the strong solution sub-cooler with generator temperature and adiabatic absorber temperature $\left(T_{\text {con }}=35^{\circ} \mathrm{C}, T_{\text {eva }}=10^{\circ} \mathrm{C}\right)$.

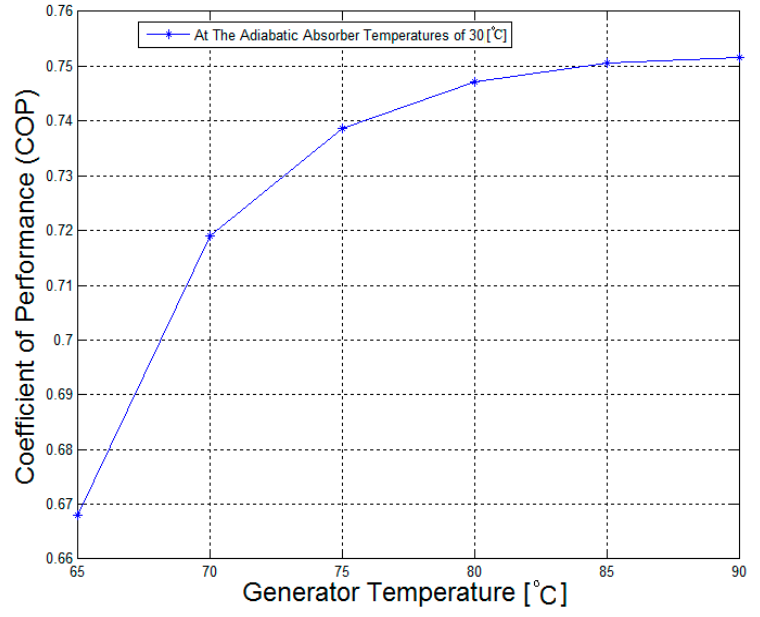

(a)

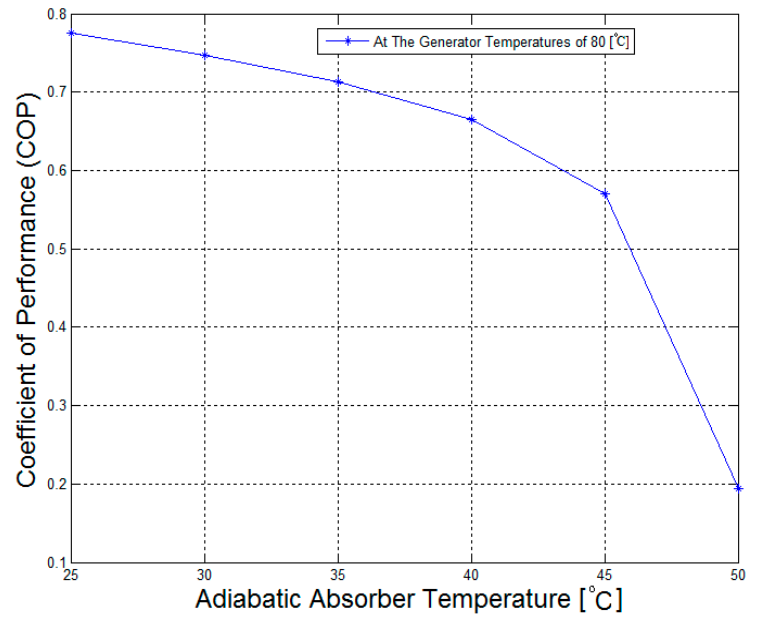

(b)

Figure 9. The influences of: (a) the generator temperature on the absorption refrigeration system performance $\left(T_{c o n}=35^{\circ} \mathrm{C}, T_{\text {eva }}=10{ }^{\circ} \mathrm{C}, T_{a b s}=30{ }^{\circ} \mathrm{C}\right)$; and $(\mathbf{b})$ the adiabatic absorber temperature on the absorption refrigeration system performance $\left(T_{c o n}=35^{\circ} \mathrm{C}, T_{\text {eva }}=10^{\circ} \mathrm{C}, T_{\text {gen }}=80^{\circ} \mathrm{C}\right)$.

As a result of this thermodynamic analysis, the temperature of the adiabatic absorber may be set at $40{ }^{\circ} \mathrm{C}$ when the generator temperature is above $75{ }^{\circ} \mathrm{C}$, for a good margin of safety against the non-operating region, as shown in Figures 3 and 10. Consequently, the temperature of $\mathrm{LiBr}$ / water solution leaving the strong solution sub-cooler is $35^{\circ} \mathrm{C}$, which can be reached easily using the same external cooling fluid that is used in the condenser. It can be noted that if, in order to optimize further the COP of the system, a lower adiabatic absorber temperature is chosen, a negligible useful refrigerating effect will result, since the cooling fluid required would be close to the evaporator temperature. 


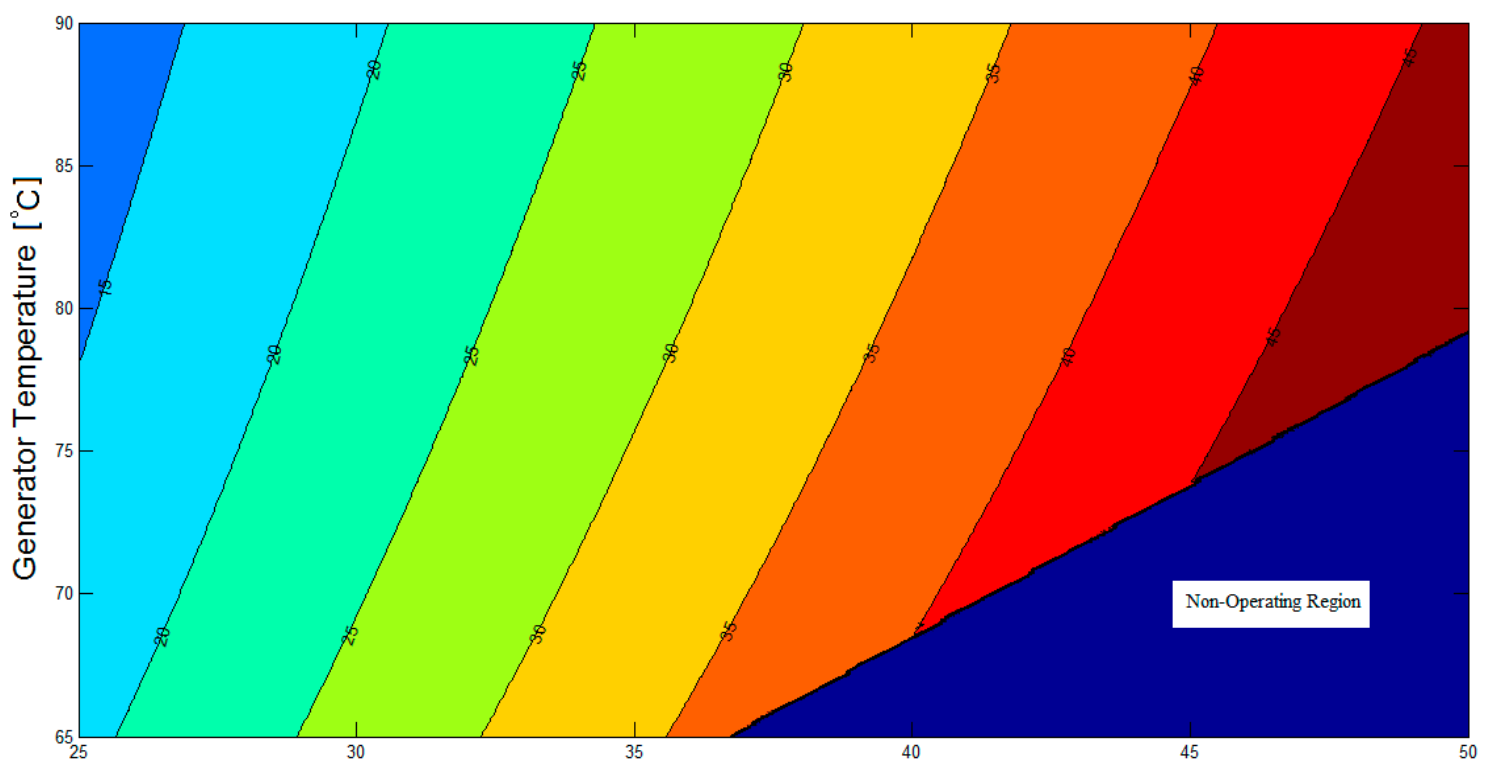

Figure 10. Contour plot of the temperature of the $\mathrm{LiBr} /$ water solution entering the adiabatic absorber $\left(T_{\text {con }}=35^{\circ} \mathrm{C}, T_{\text {eva }}=10^{\circ} \mathrm{C}\right)$.

Tables 1 and 2 show the summary of the thermodynamic analysis of the system for the optimal temperatures of the design components. The chosen temperatures of the generator, condenser, adiabatic absorber, and evaporator were $80^{\circ} \mathrm{C}, 35^{\circ} \mathrm{C}, 40{ }^{\circ} \mathrm{C}$, and $10^{\circ} \mathrm{C}$, respectively. This summary can be used to size the heat exchangers of a new $\mathrm{LiBr} /$ water absorption refrigeration system equipped with an adiabatic absorber. With reference to the numbering system shown in Figure 1, the specific enthalpy, temperature, pressure, mass flow rate, LiBr mass concentration, and fluid state have been determined and indicated for each point in the system, as shown in Table 1.

Also, Table 2 shows the heat transfer in each component in the $\mathrm{LiBr}$ /water absorption refrigeration system equipped with an adiabatic absorber, and the COP of the system. As indicated in Table 2, the COP of the absorption refrigeration cycle is apparently lower than that of the vapor-compression refrigeration cycle. However, the comparison of the two COPs should not be to the detrimental judgement of the absorption refrigeration cycle, because the two COPs are defined in different ways. The COP of the vapor-compression refrigeration cycle is defined as a ratio of the refrigeration rate to the mechanical work supplied to the compressor. In contrast, the COP of the absorption refrigeration system is defined as a combination of power cycle and refrigeration cycle [1].

Table 1. The optimal design parameters of the $\mathrm{LiBr} /$ water absorption refrigeration system equipped with an adiabatic absorber.

\begin{tabular}{|c|c|c|c|c|c|c|}
\hline Point & h (kJ/kg) & $\mathrm{T}\left({ }^{\circ} \mathrm{C}\right)$ & $\mathbf{P}(\mathbf{k P a})$ & $m(g / s)$ & $\mathrm{C}(\%)$ & Fluid State \\
\hline 1 & 2650 & 80 & 5.63 & 0.42 & 0 & Superheated vapor \\
\hline 2 & 147 & 35 & 5.63 & 0.42 & 0 & Saturated liquid \\
\hline 3 & 147 & 10 & 1.23 & 0.42 & 0 & Liquid and vapor \\
\hline 4 & 2519 & 10 & 1.23 & 0.42 & 0 & Saturated vapor \\
\hline 5 & 194 & 80 & 5.63 & 4.22 & 60.3 & Saturated liquid \\
\hline 6 & 194 & 80 & 1.23 & 4.22 & 60.3 & liquid \\
\hline 7 & 117 & 40 & 1.23 & 4.22 & 60.3 & liquid \\
\hline 8 & 85 & 36 & 1.23 & 120.24 & 55.1 & liquid \\
\hline 9 & 93 & 40 & 1.23 & 4.64 & 54.8 & Saturated liquid \\
\hline 10 & 93 & 40 & 5.63 & 4.64 & 54.8 & liquid \\
\hline 11 & 93 & 40 & 1.23 & 116.02 & 54.8 & Saturated liquid \\
\hline 12 & 93 & 40 & 1.23 & 116.02 & 54.8 & liquid \\
\hline 13 & 83 & 35 & 1.23 & 116.02 & 54.8 & liquid \\
\hline
\end{tabular}


Table 2. The heat transfer in each component and COP of the $\mathrm{LiBr} /$ water absorption refrigeration system equipped with an adiabatic absorber.

\begin{tabular}{cc}
\hline The System Components & $Q \mathbf{W})$ \\
\hline The evaporator (cooling capacity) & 1000 \\
The generator (heat input from hot resource) & 1504 \\
The condenser (heat reject to external sink) & 1055 \\
The strong solution sub-cooler (heat reject to external sink) & 1125 \\
The weak solution sub-cooler (heat reject to external sink) & 324 \\
\hline The coefficient of performance of the system (COP) $=0.66$ \\
\hline
\end{tabular}

\section{Conclusions}

A mathematical model for an $\mathrm{LiBr} /$ water absorption refrigeration system equipped with an adiabatic absorber has been presented. It has been shown that the generator temperature is an important factor in designing the absorption refrigeration system, taking into consideration the crystallization problem of the $\mathrm{LiBr}$ /water solution. The COP, the $\mathrm{LiBr}$ mass concentration of the solutions, and heat transfer in each component in the system were analyzed for specific input design parameters. The results show that an increase in generator temperature or decrease in the adiabatic absorber temperature increases the COP. Additionally, this analysis made it possible to determine the recommended generator and adiabatic absorber temperatures, which were $80^{\circ} \mathrm{C}$ and $40^{\circ} \mathrm{C}$ respectively, of such an absorption refrigeration system.

Due to the fact that the $\mathrm{LiBr}$ /water absorption refrigeration system equipped with an adiabatic absorber is influenced by many key parameters, and that it is difficult to investigate each one individually, the condenser temperature, evaporator temperature, cooling capacity, and ratio of the solution mass flow rate at the circulation pump to that at the solution pump, were kept constant at suitable values throughout this analysis. In future, this model can be used in combination with experimental data for validation purposes of the $\mathrm{LiBr} /$ water absorption refrigeration system equipped with an adiabatic absorber. Since the system shows a high value of $\mathrm{COP}$ at a low generator temperature of $80^{\circ} \mathrm{C}$, which can be reached using a solar collector, this makes it a promising application in the field of solar-powered absorption refrigeration systems. Furthermore, to improve the efficiency of the $\mathrm{LiBr}$ /water absorption refrigeration cycle equipped with an adiabatic absorber, the weak solution sub-cooler can be replaced by a solution heat exchanger between the adiabatic absorber and the generator without changing the operation process. This heat exchanger recuperates heat from the weak $\mathrm{LiBr}$ /water solution and delivers it to the strong $\mathrm{LiBr} /$ water solution before entering the generator.

Acknowledgments: The authors gratefully acknowledge the support from University of Malta.

Author Contributions: Salem M. Osta-Omar carried out the mathematical model and computations presented in this work. Christopher Micallef supervised this work. Both of the authors contributed equally to interpret the results and to write this article.

Conflicts of Interest: The authors declare no conflict of interest.

\section{Nomenclature}

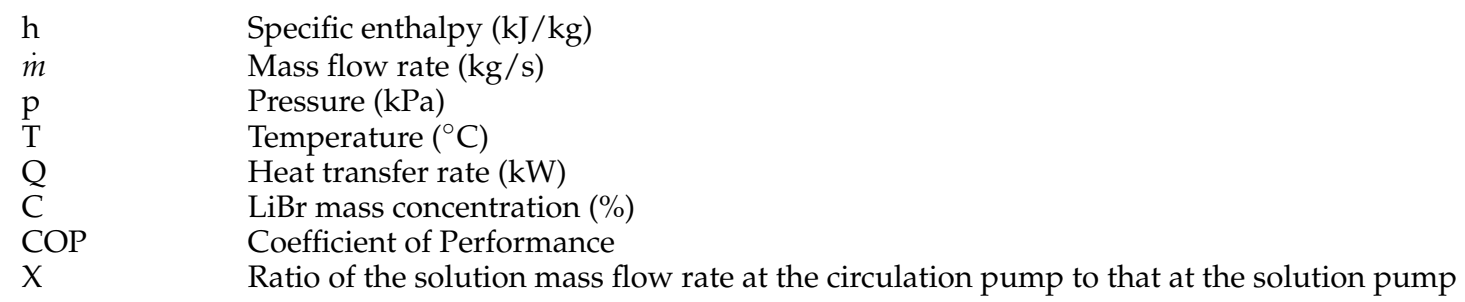


Subscript:

$\begin{array}{ll}\text { gen } & \text { Generator } \\ \text { con } & \text { Condenser } \\ \text { eva } & \text { Evaporator } \\ \text { abs } & \text { Adiabatic absorber } \\ \text { sub1 } & \text { Weak solution sub-cooler } \\ \text { sub2 } & \text { Strong solution sub-cooler } \\ 1,2,3 \ldots & \text { Represent state point in Figure 1 }\end{array}$

\section{References}

1. Jones, J.W.; Stoecker, W.F. Refrigeration and Air Conditioning, 2nd ed.; McGraw-Hill: New York, NY, USA, 1982; pp. 328-337.

2. Gutiérrez-Urueta, G.; Huicochea, A.; Rodríguez-Aumente, P.; Rivera, W. Energy and exergy analysis of water- $\mathrm{LiBr}$ absorption systems with adiabatic absorber for heating and cooling. Energy Procedia 2014, 57, 2676-2685. [CrossRef]

3. Gutiérrez-Urueta, G.; Rodríguez, P.; Venegas, M.; Ziegler, F.; Rodríguez-Hidalog, M.C. Experimental performance of a LiBr-water absorption facility equipped with adiabatic absorber. Int. J. Refrig. 2011, 34, 1749-1759. [CrossRef]

4. Eisa, M.A.R.; Holland, F.A. A study of the operating parameters in a water-lithium bromide absorption cooler. Int. J. Energy Res. 1986, 10, 137-144. [CrossRef]

5. Eisa, M.A.R.; Diggory, P.J.; Holland, F.A. Experimental studies to determine the effect of differences in absorber and condenser temperatures on the performance of water lithium bromide absorption cooler. Energy Convers. Manag. 1987, 27, 253-259. [CrossRef]

6. Micallef, D.; Micallef, C. Mathematical model of a vapour absorption refrigeration unit. Int. J. Simul. Model. 2010, 9, 86-97. [CrossRef]

7. Samanta, S.; Basu, D.N. Modeling of a solar assisted water-LiBr absorption refrigeration system for summer air conditioning of an office room. Int. J. Emerg. Technol. Adv. Eng. 2013, 3, 368-375.

8. Sharma, A.; Mishra, B.K.; Dinesh, A.; Misra, A. Design and performance study of a hot water driven 5 TR capacity absorption cooling system. Int. J. U- E-Serv. Sci. Technol. 2014, 7, 205-212. [CrossRef]

9. Marcos, J.D.; Izquierdo, M.; Palacios, E. New method for COP optimization in water-and air-cooled single and double effect LiBr-water absorption machines. Int. J. Refrig. 2011, 34, 1348-1359. [CrossRef]

10. Li, J.; Xie, X.; Yi, J. Experimental study and correlation on the falling column adiabatic absorption of water vapor into $\mathrm{LiBr}-\mathrm{H}_{2} \mathrm{O}$ solution. Int. J. Refrig. 2015, 51, 112-119. [CrossRef]

11. Zacarías, A.; Venegas, M.; Lecuona, A.; Ventas, R.; Carvajal, I. Experimental assessment of vapour adiabatic absorption into solution droplets using a full cone nozzle. Exp. Therm. Fluid Sci. 2015, 68, 228-238. [CrossRef]

12. Su, F.; Ma, H.B.; Gao, H. Characteristic analysis of adiabatic spray absorption process in aqueous lithium bromide solution. Int. Commun. Heat Mass Transf. 2011, 38, 425-428. [CrossRef]

13. González-Gil, A.; Izquierdo, M.; Marcos, J.D.; Palacios, E. New flat-fan sheets adiabatic absorber for direct air-cooled $\mathrm{LiBr} / \mathrm{H}_{2} \mathrm{O}$ absorption machines: Simulation, parametric study and experimental results. Appl. Energy 2012, 98, 162-173. [CrossRef]

14. Wang, L.; Chen, G.M.; Wang, Q.; Zhong, M. Thermodynamic performance analysis of gas-fired air-cooled adiabatic absorption refrigeration systems. Appl. Therm. Eng. 2007, 27, 1642-1652. [CrossRef]

15. American Society of Heating, Refrigerating, and Air-Conditioning Engineers. 1997 ASHRAE Handbook: Fundamentals; ASHRAE Inc.: Atlanta, GA, USA, 1997; pp. 1.14-1.18.

16. Karami, S.; Farhanieh, B. A numerical study on the absorption of water vapor into a film of aqueous $\mathrm{LiBr}$ falling along a vertical plate. Heat Mass Transf. 2009, 46, 197-207. [CrossRef]

17. American Society of Heating, Refrigerating, and Air-Conditioning Engineers. Thermophysical Properties of Refrigerants. In 2009 ASHRAE Handbook: Fundamentals; ASHRAE Inc.: Atlanta, GA, USA, 2009; pp. 70-71.

18. Kalogirou, S.; Florides, G.; Tassou, S.; Wrobel, L. Design and construction of a lithium bromide water absorption refrigerator. In Proceedings of the 7th World Congress CLIMA 2000/Napoli, Milano, Italy, 15-18 September 2001. 
19. Holmgren, M. Matlab Program for Water and Steam Properties According to IAPWS IF-97. Available online: www.mathworks.com/ (accessed on 5 August 2016).

20. MATLAB, version 7.10.0; Computer software; The MathWorks Inc.: Natick, MA, USA, 2010.

(C) 2016 by the authors; licensee MDPI, Basel, Switzerland. This article is an open access article distributed under the terms and conditions of the Creative Commons Attribution (CC-BY) license (http://creativecommons.org/licenses/by/4.0/). 